\title{
Ventilatory support and pharmacological treatment of patients with central apnoea or hypoventilation during sleep
}

\author{
D. Pevernagie*, J.P. Janssens" ${ }^{\#}$ W. De Backer", M. Elliott ${ }^{+}$, \\ J. Pepperell ${ }^{\S}$ and S. Andreas
}

ABSTRACT: The concept of central sleep apnoea or hypoventilation encompasses hypercapnic central hypoventilation, such as obesity hypoventilation syndrome and eucapnic or hypocapnic central sleep apnoea.

Among subjects with eucapnic or hypocapnic central sleep apnoea, several therapeutic options are available for those with Cheyne-Stokes respiration (CSR). CSR is frequent in patients with New York Heart Association stage III and IV chronic heart failure, and in various neurological disorders. In these patients, treatment modalities include optimising cardiac condition and drugs, such as theophylline, acetazolamide and/or oxygen. Ventilatory support, such as nasal continuous positive airway pressure (CPAP), bi-level pressure support, or adaptive servoventilation (ASV), has been shown to improve CSR in patients with cardiac failure; however, convincing evidence that nasal CPAP improves life expectancy in these patients is lacking. Nevertheless, the treatment of associated obstructive sleep-disordered breathing is indicated per se, as it may improve cardiac function.

There is currently no proof that bi-level ventilation is superior to nasal CPAP. The few available studies that have focused on ASV have shown satisfactory control of CSR in cardiac failure patients. While ASV is not a first-line treatment choice, it appears to be superior to oxygen, CPAP and bi-level pressure ventilation in controlling the apnoea/hypopnea index and probably sleep fragmentation. As yet there are no data on mortality and, as such, firm conclusions cannot be drawn as to the role of ASV in the management of cardiac failure patients suffering from CSR.

Obesity-related hypoventilation has increased dramatically over recent decades due to the epidemic increase in obesity in the developed countries. Obesity hypoventilation syndrome predisposes to the development of pulmonary hypertension and cor pulmonale. Noninvasive home ventilation is increasingly applied in obese patients with hypercapnic respiratory failure, however, initial mechanical ventilatory support can be reduced to nasal continuous positive airway pressure in only a subset of these individuals.

KEYWORDS: Bi-level positive airway pressure, central sleep apnoea, continuous positive airway pressure, hypoventilation, pharmacological treatment, sleep-disordered breathing

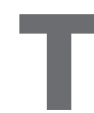

emporary cessation of neuronal activity in the respiratory centres in the brainstem is the basic mechanism of central sleep apnoea. In contrast, obstructive sleep apnoea is characterised by ongoing respiratory effort while the upper airway is closed (fig. 1). A combination of both types, known as mixed-sleep apnoea, is also frequently observed in clinical practice. Central sleep-disordered breathing (SDB) includes hypercapnic central sleep apnoea, which is part of the spectrum of the sleep-related alveolar hypoventilation syndromes, and eucapnic/hypocapnic central sleep apnoea, which physiologically results from the unmasking of the "carbon dioxide $\left(\mathrm{CO}_{2}\right)$ threshold" during sleep. In the latter category, a peculiar type of cyclic breathing, with waxing and waning breathing patterns, is known as "Cheyne-Stokes respiration" (CSR). CSR is a respiratory complication of chronic heart failure (CHF) and of various neurological disorders, including cerebro-vascular disease. Different treatment options and strategies are available for central sleep apnoea syndromes. The relative importance of continuous positive airway pressure (CPAP), bi-level positive airway pressure (BiPAP),
AFFILIATIONS

*Dept of Respiratory Diseases and Sleep Medicine Centre, Ghent University Hospital, Ghent, 'Service of Pneumology, UZ Antwerpen, Edegem, Belgium. "Division de Pneumologie, Hôpital Cantonal Universitaire, Geneva, Switzerland

${ }^{+}$Dept of Respiratory Medicine, St. James's University Hospital, Leeds,

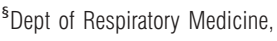
Taunton \& Somerset Hospital, Taunton, UK, and

${ }^{f}$ Lungenfachklinik Immenhausen, Immenhausen, Germany.

CORRESPONDENCE

D. Pevernagie

Dept of Respiratory Diseases and

Sleep Medicine Centre Ghent University Hospital De Pintelaan 185 9000 Ghent

Belgium

Fax: 3292402341

E-mail: Dirk.Pevernagie@UGent.be

STATEMENT OF INTEREST

The present article was presented as part of the international symposium "Respiratory somnology: a clinical update", sponsored by GlaxoSmithKline, Belgium. J. Pepperell has received research funding and travel expenses from ResMed.

S. Andreas has received consultancy fees from Sanofi Synthelabo and a lecturing fee from Respironics. 
adaptive servo-ventilation (ASV) and pharmacological regimens in the treatment of central sleep apnoea will be discussed in the present article.

SDB in obese patients poses a particular problem. Some morbidly obese patients not only suffer from obstructive sleep apnoea/hypopnoea syndrome (OSAHS), but also develop chronic hypercapnic respiratory failure with diurnal and nocturnal alveolar hypoventilation. This condition is known as the "obesity-hypoventilation syndrome" (OHS) [1]. It results from a combination of decreased chest wall compliance related to adiposity, increased dynamic upper airway

a)

EEG

Airflow

Effort: rib cage

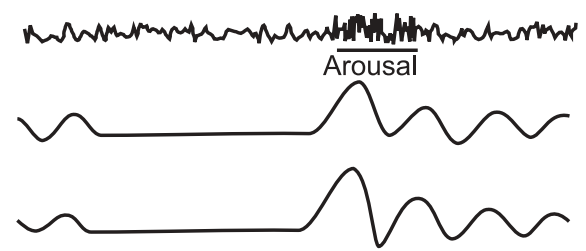

Effort: abdomen

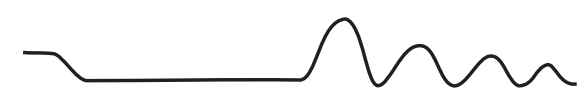

Effort:

oesophageal

pressure

$\mathrm{CmH}_{2} \mathrm{O}$

Oxygen

saturation $\%$

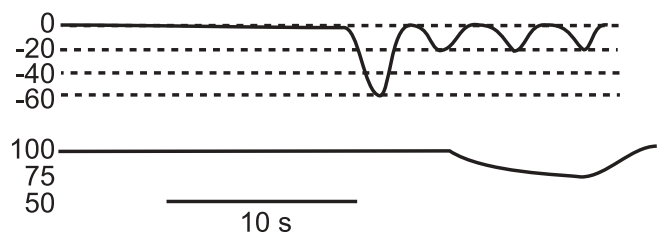

b)

EEG

Airflow

Effort: rib cage

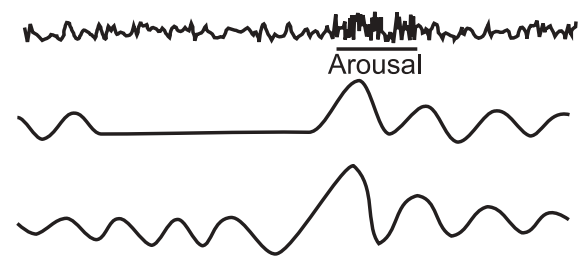

Effort: abdomen

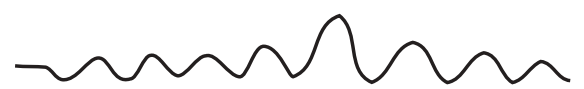

Effort:

oesophageal

pressure

$\mathrm{CmH}_{2} \mathrm{O}$

Oxygen

saturation $\%$

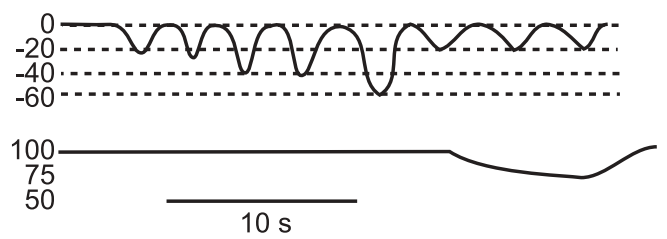

FIGURE 1. a) Central sleep apnoea. A stopped-breathing episode (zero airflow) is associated with a cessation in respiratory effort. Respiratory activity is absent in the thoracic and abdominal movement sensors and in the oesophageal pressure lead. Breathing resumes after an electroencephalogram (EEG) arousal. b) Obstructive sleep apnoea. Cessation of breathing (zero airflow) is evident despite ongoing respiratory effort. Respiratory activity continues in the thoracic and abdominal movement sensors. The oesophageal pressure lead shows increasing inspiratory effort. Breathing resumes only after an EEG arousal. $1 \mathrm{cmH}_{2} \mathrm{O}=0.1 \mathrm{kPa}$. resistance (especially during sleep) and blunting of the ventilatory drive. It is unclear whether nasal CPAP should be the first-line treatment in all of these patients, or whether bilevel pressure support ventilation is the treatment of first choice.

\section{PATHOPHYSIOLOGY OF CENTRAL NONHYPERCAPNIC SLEEP APNOEA}

During sleep, breathing is controlled by afferent impulses coming from peripheral and central chemoreceptors. The wakefulness drive, comprising impulses from higher centres in the brainstem and cortex, disappears at sleep onset. As a result, ventilatory output is decreased and ventilation is sustained by this reflex control system. Sensitivity of chemoreceptors also decreases during sleep, although variably according to sleep stage. Hypercapnic ventilatory response has been shown to be reduced in all sleep stages, and the decrease is most pronounced during rapid eye movement (REM) sleep. Hypoxic ventilatory response also decreases, reaching two-thirds of the waking value during non-REM sleep. The overall effect of chemical stimulation on breathing during sleep depends, on one hand, on the magnitude of the reduction of the receptor sensitivity and, on the other hand, on the degree of hypoxaemia/hyperoxia or hypercapnia/hypocapnia. Ventilatory rhythmogenesis, in the absence of stimuli associated with wakefulness, seems to be critically dependent on chemoreceptor stimulation.

During non-REM sleep, central apnoea can occur after hyperventilation when arterial carbon dioxide tension $\left(\mathrm{Pa}_{\mathrm{a}} \mathrm{CO}_{2}\right)$ drops below a critical value, the so-called apnoeic threshold usually located $<4.7 \mathrm{kPa}$. "Unmasking" of the $\mathrm{CO}_{2}$ apnoeic threshold occurs at the onset of sleep and leads to cessation of ventilation [2]. Normal individuals seem to be protected from developing this type of central apnoea by a preceding increase in end-tidal $\mathrm{CO}_{2}$ tension, often occurring at sleep onset. As ventilatory load compensation is reduced during sleep, and upper airway resistance is increased, resulting hypoventilation seems to be implicated in the observed $\mathrm{CO}_{2}$ retention. The higher the $\mathrm{CO}_{2}$ apnoeic threshold, the more central apnoeas will occur during sleep. The significance of the $\mathrm{CO}_{2}$ threshold is best illustrated during breathing at high altitude: chronic hyperventilation due to the acclimatisation process causes $\mathrm{Pa}_{\mathrm{a}} \mathrm{CO}_{2}$ to drop below the apnoeic threshold. The apnoeic threshold is also stagedependent. In REM sleep, both phasic and tonic, there is apparently no apnoeic threshold. Arousal can trigger hyperventilation and induce hypocapnia that will lead to an apnoea when sleep resumes and the $\mathrm{Pa}_{\mathrm{a}} \mathrm{CO}_{2}$ decreases below the apnoeic threshold.

Lung volume may influence oxygen $\left(\mathrm{O}_{2}\right)$ saturation and baseline chemical drives, but it may also influence pharyngeal cross-sectional area, which decreases when functional residual capacity (FRC) decreases. All these basic physiological principles are discussed in more detail in specific reviews [3-5]. Until recently, upper airway patency was not considered relevant in the pathogenesis of central apnoea; however, in recent years, it has become clear that the upper airway may close during central apnoea $[6,7]$. The occlusion of the upper airway may provide another stimulus for upper airway receptors and provoke upper airway reflexes with associated apnoeas [8]. 
A peculiar type of hypocapnic central sleep apnoea, characterised by waxing and waning breathing patterns, is known as CSR. CSR occurs physiologically at high altitude, and is related to hypocapnia induced by hyperventilation in response to hypoxia. CSR is also a respiratory complication of CHF, and of various neurological disorders including cerebro-vascular disease. It is common in patients with severe CHF. Up to $45 \%$ of patients with a left ventricular ejection fraction of $\leqslant 40 \%$ may suffer from this breathing disorder during sleep, impairing quality of life and worsening survival $[9,10]$. CSR in CHF is more common in males, with advancing age, more severe heart failure and in patients with atrial fibrillation [11, 12]. Daytime hyperventilation may predispose to CSR by lowering $\mathrm{CO}_{2}$ towards the apnoeic threshold. Besides the unveiling of this $\mathrm{CO}_{2}$ threshold, several other mechanisms are involved in increasing loop gain and perpetuating the breathing instability [13]. These include increased hypercapnic ventilatory responses, increased intrathoracic lung water and blood volume, stimulation of juxta-capillary receptors by interstitial oedema, reduced lung volumes, decreased $\mathrm{O}_{2}$ uptake and $\mathrm{CO}_{2}$ production with age, reduced $\mathrm{O}_{2}$ and $\mathrm{CO}_{2}$ stores that increase plant gain (i.e. responsiveness of blood gases to ventilatory changes), sleep-stage transitions with associated respiratory drive changes, delayed circulation time and abnormal upper airway mechanics and reflexes.

\section{TREATMENT OPTIONS OF CENTRAL NONHYPERCAPNIC SLEEP APNOEA \\ General considerations}

When looking for specific treatment options for central apnoea, the pathogenic mechanisms mentioned above must be taken into account. All treatments described will interfere with one of the above mechanisms. Two main approaches can be considered. The first is to decrease chemical drive; the second is to try to lower the apnoeic threshold for $\mathrm{CO}_{2}$. Lowering hypoxic ventilatory response can be obtained by pharmacological interventions (e.g. codeine) that decrease the sensitivity of the peripheral chemoreceptors. However, more conveniently, breathing $\mathrm{O}_{2}$ decreases the stimulation of the peripheral chemoreceptors, and thus alveolar ventilation, leading to higher carbon dioxide tension $\left(\mathrm{PCO}_{2}\right)$ values. The latter prevents the $\mathrm{CO}_{2}$ level from dropping below the threshold. $\mathrm{O}_{2}$ breathing will only be effective in patients with relatively high hypoxic ventilatory responses [5]. Most effective, however, are interventions influencing the $\mathrm{CO}_{2}$ threshold itself. Noninvasive ventilation is certainly another option that has been reported to be effective in some patients. CPAP may increase $\mathrm{CO}_{2}$ by inducing some rebreathing, but it may also lower basic ventilatory drive, probably one of the more important mechanisms $[14,15]$.

In summary, the choice of treatment options for idiopathic central sleep apnoea must depend on the insight into the pathogenetic mechanisms in general, and also those active in the patients requiring treatment.

\section{Pharmacological treatment of CSR}

\section{Benzodiazepines}

Temazepam has been shown to reduce the respiratory related arousals, but not to have an impact on CSR [16]; thus, this therapy cannot be recommended.

\section{Theophylline}

Theophylline, a nonselective phophodiesterase inhibitor, inhibits inflammatory mediators at supra-therapeutic concentrations. Furthermore, it is an adenosine receptor antagonist [17]. Interestingly, CHF patients have a 3-4-fold increase in plasma adenosine levels [18]. Adenosine inhibits respiration and mediates excitatory effects by peripheral chemoreceptors [19]. Accordingly, theophylline increases minute ventilation, lowers transcutaneous $\mathrm{CO}_{2}$ and nearly doubles plasma renin concentration in both healthy subjects and heart failure patients [20]. These effects on ventilation and neurohumoral activation might be disadvantageous in patients with severe $\mathrm{CHF}$.

The use of short-term theophylline in CHF patients with CSR was associated with a significant reduction in the apnoea/ hypopnea index (AHI), but no reduction in the frequency of arousals or improvements in sleep structure or cardiac function [21]. In a case report, theophylline was successfully used to treat life-threatening central apnoeas in the setting of normal ventricular function [22].

\section{Acetazolamide}

Acetazolamide is a carbonic anhydrase inhibitor that stimulates central respiratory drive by causing a metabolic acidosis [23]. In periodic breathing at high altitude, acetazolamide reduces the frequency of central apnoeas and hypopnoeas [24]. In a study of normal subjects with induced periodic breathing during sleep, NAKAYAMA et al. [25] showed that due to metabolic acidosis induced by acetazolamide, the difference between the prevailing $\mathrm{PCO}_{2}$ and the apnoeic threshold $\mathrm{PCO}_{2}$ increased and sleep apnoea was reduced.

In a double-blind, randomised controlled trial in heart failure patients, acetazolamide reduced CSR and subjective perception of daytime sleepiness was improved [26]. However, some caution is necessary as metabolic acidosis and induced hyperventilation may be disadvantageous in $\mathrm{CHF}$ patients.

DE BACKER et al. [23] have shown that lowering the $\mathrm{CO}_{2}$ threshold with acetazolamide is highly effective in preventing central apnoeas. Moreover, the effects induced by acetazolamide are long-lasting, suggesting that this compound induces a resetting of the central drive (plasticity of the control system).

\section{$\mathrm{O}_{2}$}

The rationale for using $\mathrm{O}_{2}$ is that it increases $\mathrm{O}_{2}$ and $\mathrm{CO}_{2}$ stores and suppresses the peripheral chemoreceptor drive, thereby damping the respiratory control system. All clinical studies showed that nasal $\mathrm{O}_{2}$ significantly improves periodic breathing and virtually eliminates arterial desaturation [27-33]. In a recent randomised trial, benefit over standard medical care in left ventricular function and quality-of-life scores was demonstrated [34].

Improvement in sleep quality was found in some [28, 30, 31], but not all studies [32, 35]. In one randomised, placebocontrolled study of intranasal $\mathrm{O}_{2}$ given for 1 week, an increase in peak $\mathrm{O}_{2}$ consumption during exercise and a normalisation of the hypercapnic ventilatory response was reported [30]. Another study documented significant reductions in overnight urinary norepinephrine excretion in patients with stable CHF and CSR while they were on nocturnal $\mathrm{O}_{2}$ during a 4-week study [32]. In a recent study of 12-weeks' duration, nocturnal 
$\mathrm{O}_{2}$ had no effect on either ventilatory efficiency during exercise (shown by the minute ventilation $/ \mathrm{CO}_{2}$ production slope) or left ventricular ejection fraction [33]. Increased afterload following $\mathrm{O}_{2}$ was reported, however, this response was seen only with the acute administration of $100 \% \mathrm{O}_{2}[36,37]$.

In conclusion, nocturnal $\mathrm{O}_{2}$ clearly reduces CSR in a number of well-controlled but small studies. However, there is no convincing evidence of positive effects on cardiac function. This must be seen in the context of a low propensity of industry to fund adequately powered studies.

\section{$\mathrm{CO}_{2}$}

In $\mathrm{CHF}$, nocturnal $\mathrm{CO}_{2}$ plus $\mathrm{O}_{2}$ eliminated CSR and increased arterial $\mathrm{O}_{2}$ saturation, as well as mean transcutaneous $\mathrm{CO}_{2}$ tension, but markedly increased sympathetic activation [38] and is thus disadvantageous in CHF.

\section{BI-LEVEL PRESSURE SUPPORT VENTILATION VERSUS CPAP IN PATIENTS WITH CSR RESPIRATION}

CPAP and time-controlled bi-level pressure support ventilation are both used to treat SDB in other conditions. CPAP requires a spontaneously breathing patient and would be expected to be ineffective for central apnoeas, whereas timed bi-level pressure support ventilation is able to ventilate a patient even in the absence of spontaneous respiratory effort and is theoretically, at least superficially, a more logical mode. However, bi-level pressure support ventilation could worsen CSR by reducing $\mathrm{CO}_{2}$ levels further below the apnoeic threshold.

There are a number of studies investigating the effect of CPAP in patients with CSR [27, 39-41], but few using bi-level pressure support ventilation. In a case series of nine patients with symptomatic CSR, diagnosed on overnight polysomnography [42], noninvasive pressure preset ventilation almost completely abolished CSR in all patients with a reduction in AHI from $49 \pm 10$ to $6 \pm 5$ events $\cdot h^{-1}(p<0.001)$. Arousal index was markedly decreased from $42 \pm 6$ to $17 \pm 7$ events $\cdot h^{-1}(p<0.001)$ and sleep quality showed a trend towards improvement.

In a nonrandomised controlled trial [43], seven patients received only conventional medications and a group of seven patients received bi-level pressure support ventilation in addition. In the control group, there were no significant changes in cardiac function, whereas in the group that received bi-level pressure support ventilation, there were significant improvements in left ventricular ejection fraction (from $36.3 \pm 2.9 \%$ to $46.0 \pm 4.0 \%, \mathrm{p}=0.02$ ), brain natriuretic peptide (from $993.6 \pm 332.0 \mathrm{pg} \cdot \mathrm{mL}^{-1}$ to $474.0 \pm 257.6 \mathrm{pg} \cdot \mathrm{ml}^{-1}, \mathrm{p}=0.02$ ) and New York Heart Association (NYHA) functional class (from $3.1 \pm 0.1$ to $2.1 \pm 0.1, \mathrm{p}=0.03$ ).

In a short-term, randomised, controlled crossover trial, KoeHnLein et al. [44] compared 14-day cycles of CPAP $(0.85 \mathrm{kPa})$ or bi-level pressure support ventilation (inspiratory positive airway pressure $0.85 \mathrm{kPa}$ and expiratory positive airway pressure $0.30 \mathrm{kPa}$ ) in random order. A total of 16 patients with heart failure completed the study. There were no differences between the two modes, with both improving various measures during sleep and daytime. The pre-treatment AHI of $26.7 \pm 10.7$ events $\cdot h^{-1}$ was reduced by both CPAP and bi-level pressure support ventilation to $7.7 \pm 5.6(\mathrm{p}<0.001)$ and $6.5 \pm 6.6$ events $\cdot h^{-1}(p<0.001)$, respectively. The arousal index fell from $31.1 \pm 10.0$ to $15.7 \pm 5.4$ events $\cdot h^{-1} \quad(p<0.001)$ and $16.4 \pm 6.9$ events $\cdot h^{-1}(p<0.001)$, respectively. Significant and equal improvements with CPAP and bi-level pressure support ventilation were found for sleep quality, daytime fatigue, circulation time and NYHA class.

The available data suggest equivalence of CPAP and bi-level pressure support ventilation. For reasons of cost, CPAP should be the mode of choice with bi-level pressure support ventilation reserved for those intolerant of CPAP. The role of ASV will be discussed elsewhere. A key issue, however, is whether any form of assisted ventilation is indicated in patients with CSR. In a large multicentre study of 258 patients, randomised to conventional therapy with or without CPAP (Canadian Continuous Positive Airway Pressure for Patients with Central Sleep Apnea and Heart Failure (CANPAP) trial), there were no differences between the control group and the CPAP group in the number of hospitalisations, quality of life or atrial natriuretic peptide levels [45]. An early divergence in survival rates favoured the control group, but after 18 months the divergence favoured the CPAP group. Adverse haemodynamic effects of CPAP have been seen in patients with atrial fibrillation [46] and these patients were not excluded in this study. The overall event rates (death and heart transplantation) did not differ (32 versus 32 events, respectively; $\mathrm{p}=0.54$ ). Although CPAP improved sleep-related abnormalities of breathing, increased ejection fraction, lowered catecholamine levels and increased walking distance, it did not affect survival [45].

The abnormality of ventilation during sleep is primarily a consequence of a failing heart and optimisation of cardiac function should be the first aim of therapy. For a subgroup of patients, cardiac resynchronisation therapy has been shown to reduce CSR $[47,48]$ and improve exercise capacity and quality of life. One area in which CPAP clearly has a role is in the treatment of co-existent obstructive sleep apnoea in patients who also have cardiac failure [49]. In a 3-month parallel group study [50], patients with $\mathrm{CHF}$ and obstructive sleep apnoea (mean AHI 28 events $\cdot h^{-1}$, Epworth score 10 ) were treated with CPAP or conventional therapy. CPAP treatment was associated with significant improvements in left ventricular ejection fraction $(\Delta 1.5 \pm 1.4 \%$ versus $5.0 \pm 1.0 \%$, respectively; $\mathrm{p}=0.04)$, reductions in overnight urinary norepinephrine excretion $\left(\Delta 1.6 \pm 3.7\right.$ versus $-9.9 \pm 3.6 \mathrm{nmol} \cdot \mathrm{mmol}^{-1}$ creatinine, respectively; $\mathrm{p}=0.036$ ), and improvements in quality of life. Furthermore, CPAP has been shown to reduce transmural pressure and left ventricular afterload in CHF.

In conclusion, there is insufficient evidence to recommend bilevel pressure support ventilation rather than CPAP in patients with CSR. Indeed the question of whether positive pressure ventilation is indicated for any patients with CSR remains open, with current evidence suggesting not. The treatment of symptomatic obstructive sleep apnoea in patients with significant cardiac failure is indicated in its own right, but patients may gain additional benefits in terms of improved cardiac function. Whether patients with heart failure who also have mild OSAHS should be treated with CPAP remains open to debate.

\section{ASV IN PATIENTS WITH CSR}

CSR is related to heart failure severity and pulmonary capillary wedge pressure. Control of heart failure can reduce CSR and 
all patients should have their medical treatment optimised before the CSR is treated. Several medical treatments that have been shown to reduce CSR will be reviewed elsewhere in the present article. Current therapeutic options include angiotensin converting enzyme inhibitors [28], $\beta$-blockers [51, 52], diuretics [53], digoxin, pacemakers [47], valve surgery [54] and heart and lung transplantation [53]. If these interventions fail to control CSR, $\mathrm{O}_{2}$ treatment may stabilise CSR prior to trials of CPAP, bi-level pressure support ventilation or ASV.

ASV aims to stabilise periodic breathing, either in central sleep apnoea or CSR, and predominantly in patients with CHF. The ventilator measures breathing frequency and tidal volume. A moving average minute volume is calculated. ASV aims to deliver $90 \%$ of this recent minute volume to mimic the usual reduction in ventilation with sleep onset that allows $\mathrm{CO}_{2}$ levels to rise. During sleep, the initial part of the inspiratory effort predicts tidal volume. Where tidal volumes are adequate to achieve the target ventilation ASV delivers the minimum pressure support. With CSR, as the central apnoea progresses ASV delivers variable pressure support to maintain the target minute ventilation by supporting tidal volume on a breath-bybreath basis. Where there is absolute apnoea or a respiratory pause, the target minute ventilation is delivered by a combination of the highest pressure support and a backup breath rate that mirrors recent respiratory frequency. With this approach, fluctuations in blood gas tensions and sleep stage are smoothed out allowing stabilisation of the periodic breathing and reduced arousal. The ASV is set to a default standard value of $0.5 \mathrm{kPa}$ expiratory positive pressure, and to deliver extra inspiratory pressure support varying between a minimum of $0.3 \mathrm{kPa}$ and a maximum of $1.0 \mathrm{kPa}$. Using these default settings, expiratory positive pressure stays at $0.5 \mathrm{kPa}$ and inspiratory positive pressure varies between 0.8 and $1.5 \mathrm{kPa}$ depending on the patient's own inspiratory effort.

There are several nonrandomised, uncontrolled cohort studies of ASV in CSR for durations of 3-24 months [55, 56]. TOPFER et al. [55] reported 11 patients with CSR due to heart failure (ejection fraction $<40 \%$ ) treated with ASV for a period of 6 weeks. The average usage time of ASV was $5.8 \pm 2.1 \mathrm{~h} \cdot$ day $^{-1}$. With ASV, both AHI and arousal index were reduced. The afternoon nap duration was significantly less, as was the number of nocturnal voidings. There was a significant improvement in heart-specific quality of life, as measured with the Minnesota Living with Heart Failure Questionnaire [55]. A further uncontrolled 12-month study [56] of ASV in 21 subjects with moderate-to-severe CSR confirmed a reduction in AHI from 44.3 to 3.4 events $\cdot h^{-1}(p<0.0001)$. Nightly use averaged $4.3 \mathrm{~h} \cdot \mathrm{day}^{-1}$. The authors also reported improved oxygenation, increased slow-wave sleep, reduced arousal index, improved cardiac function both on echocardiograms, and increased 6-min walk distance. The heart failure qualityof-life scales and Epworth sleepiness scale were not significantly different pre- and post-study [56]. Of the randomised controlled trials in this area of study, the first compared shortterm ASV with baseline, $\mathrm{O}_{2}$ therapy alone, CPAP and bi-level pressure support ventilation. TESCHLER et al. [57] reported that ASV treats sleep apnoea and improves sleep better than control, $\mathrm{O}_{2}$ and CPAP. AHI reduced from 44.5 events $\cdot h^{-1}$ untreated to 28.2 events $\cdot \mathrm{h}^{-1}$ on $\mathrm{O}_{2}$ and 26.8 events $\cdot \mathrm{h}^{-1}$ on CPAP (both $\mathrm{p}<0.001$ versus control), 14.8 events $\cdot \mathrm{h}^{-1}$ on bi-level pressure support ventilation, and 6.3 events $\cdot \mathrm{h}^{-1}$ on ASV $(\mathrm{p}<0.001$ versus bi-level). Arousal index decreased from 65.1 events $\cdot h^{-1}$ untreated to 29.8 events $\cdot h^{-1}$ on $\mathrm{O}_{2}$ and 29.9 events $\cdot h^{-1}$ on CPAP, to 16.0 events $\cdot h^{-1}$ on bi-level pressure support ventilation and 14.7 events $\cdot h^{-1}$ on ASV $(p<0.01$ versus all except bi-level). There were large increases in slow-wave and rapid eye movement sleep with ASV but not with $\mathrm{O}_{2}$ or CPAP. All subjects preferred ASV to CPAP. In a 2-yr follow-up report published in abstract form, the authors suggested that, compared with $\mathrm{O}_{2}$, ASV improved AHI, arousal frequency, exercise capacity, ejection fraction and hospital admissions [58].

In a second, randomised controlled trial, 1-month of therapeutic ASV was compared with a sub-therapeutic control ASV device in 30 subjects with CSR (mean \pm SD AHI $29.1 \pm 22.7$ events $\cdot h^{-1}$ ), and stable symptomatic chronic heart failure (NYHA class II-IV). Compared with control, therapeutic ASV treatment improved objective daytime sleepiness and reduced brain natriuretic peptide, catecholamines and ventilation; although there was no change in cardiac function or quality-of-life measures [59]. More recently, PHILIPPE et al. [60] have reported a 6-month randomised trial of ASV versus CPAP in 25 patients with moderate-to-severe heart failure. Compared with CPAP, the authors report that ASV was better tolerated and improved AHI, left ventricular ejection fraction and quality of life [60].

In summary, there is good evidence that ASV controls central sleep apnoea and CSR. This treatment is superior to $\mathrm{O}_{2}, \mathrm{CPAP}$ and bi-level pressure support ventilation in controlling $\mathrm{AHI}$ and probably sleep fragmentation. There is a suggestion that ASV improves quality-of-life scores and cardiac function, but this has yet to be proven in large, prospective, randomised trials.

\section{CPAP VERSUS BI-LEVEL PRESSURE SUPPORT VENTILATION FOR OHS}

Patients with OHS have a decreased FRC and vital capacity, an increased work of breathing due to reduced compliance and increased elastic recoil of their respiratory system. The upper airway resistance is increased in patients with associated OSAHS. Decreased ventilation/perfusion ratios in the lower lung zones and alveolar hypoventilation both contribute to impaired gas exchange. Ventilatory responses to hypercapnia and hypoxia are blunted. Resistance to the central nervous system effects of leptin has been suggested as a cause of decreased ventilatory response to $\mathrm{CO}_{2}$. OSAHS is often, but not always, associated with OHS. Without adequate treatment, patients with OHS develop pulmonary hypertension, cor pulmonale and recurrent episodes of hypercapnic respiratory failure. Indeed, obesity-associated hypoventilation without ventilatory support is associated with excess morbidity and mortality (23\% at 18 months) [61].

One of the most striking findings in a study of home noninvasive ventilation (NIV) in the Lake Geneva area [62] was the impressive increase in use of NIV for patients with OHS over the 8-yr follow-up period. Patients with OHS were seldom prescribed NIV up to 1994. As of 1996, OHS became the most common indication for NIV in the Lake Geneva area study [62]. Interestingly, patients with OHS were not mentioned in either the French study on home NIV by LEGER et al. 
[63] or in the British study by SIMONDS et al. [64]. A report of the French organisation for home care (Association Nationale pour le Traitement a Domicile des Insuffisants Respiratoires (France) ANTADIR) published in 1998 did not mention OHS patients treated with NIV; only $2.7 \%$ of patients with OSAHS were treated with bi-level pressure support ventilation, i.e. $8.5 \%$ of all patients under home mechanical ventilation in 1998 . In fact, only one recent study of 30 patients treated with home mechanical ventilation included a substantial number $(26 \%)$ of patients with OHS [65]. Thus, the use of NIV in OHS is a rather recent phenomenon in the history of home NIV.

\section{EPIDEMIOLOGY OF OBESITY IN SWITZERLAND AND OTHER EUROPEAN COUNTRIES}

A Swiss National Health Survey [66] reported a prevalence of grade II obesity (body mass index (BMI) $>30 \mathrm{~kg} \cdot \mathrm{m}^{-2}$ ) of $5.4 \%$ for the whole population; depending on age groups, the range of prevalence of grade II obesity was $1.1-10.2 \%$ for males and $0.7-8.7 \%$ for females. However, prevalence of grade III obesity (BMI $>40 \mathrm{~kg} \cdot \mathrm{m}^{-2}$ ) was only $0.3 \%$ for males and $0.2 \%$ for females. Prevalence rates of grade II obesity were similar to data reported from the Netherlands $(7.4 \%$ for males, $9.0 \%$ for females), Sweden (5.3\% for males, 9.1\% for females), and lower than figures from England (13\% for males, $15 \%$ for females) or Germany $(17.2 \%$ for males, $19.3 \%$ for females). Globally, in Europe, there was a clear trend for an increase in the prevalence of obesity, most often increasing during the 1980s [67]. The major increase in class III obesity reported in the USA over the past $40 \mathrm{yrs}$ is noteworthy [68]. Although US figures could well account for the spectacular rise of OHS patients under NIV (30\% of US adults had class II obesity in 2002, according to the Centers for Disease Control and Prevention), prevalence of class II and class III obesity in Europe do not suffice to explain this trend. Increasing awareness of obesityrelated respiratory disorders by general practitioners and pulmonary physicians is certainly contributive to the increasing use of NIV in OHS.

\section{VENTILATORY SUPPORT IN PATIENTS WITH OHS: CPAP, BI-LEVEL PRESSURE SUPPORT VENTILATION OR VOLUMETRIC NIV?}

Positive pressure support in OHS decreases upper airway resistance during sleep (pneumatic splinting), thus decreasing the nocturnal work of breathing in subjects with associated OSAHS, increases FRC and thus improves ventilation/perfusion matching, and, when using a bi-level pressure support ventilation device, unloads the respiratory muscles and increases nocturnal ventilation to improve daytime and nighttime $\mathrm{Pa}, \mathrm{CO}_{2}$. As strength of respiratory muscles is preserved in most patients with OHS [62], and NIV has not been shown to change the compliance of the respiratory system in OHS, NIV most probably improves daytime arterial blood gases through a resetting of respiratory centres and target values for $\mathrm{Pa}, \mathrm{CO}_{2}$. Recent studies have documented an improvement in ventilatory response to $\mathrm{CO}_{2}$ in subjects with OHS treated by bi-level pressure support ventilation $[69,70]$.

The fact that the bi-level pressure support ventilation may unload the respiratory muscles in patients with class III obesity was demonstrated by PANKOW et al. [71], who studied 18 patients with simple obesity, OHS or OSAHS, measured trans-diaphragmatic pressure and pressure-time index, and, with low inspiratory positive airway pressure values up to $1.2 \mathrm{kPa}$, found a $46 \%$ reduction in diaphragmatic activity.

The first report of an alternative treatment to tracheostomy of patients with severe OHS, cardio-respiratory failure and associated OSAHS (Pickwickian syndrome) was published by SulLIVAN et al. [72] in 1983. Low levels of CPAP apparently improved daytime and nocturnal hypoventilation, and nocturnal arterial oxygen saturation $\left(\mathrm{Sa}_{\mathrm{a}} \mathrm{O}_{2}\right)$. With the advent of the BiPAP, SANDERS and KERN [73] established that bi-level pressure ventilation could be used to treat OSAHS at lower levels of expiratory positive airway pressure, improving acceptance to treatment. More recent reports showed that short-term NIV could successfully treat patients with OHS, OSAHS and hypercapnic respiratory failure, with a persistent correction of daytime hypercapnia [74]. PIPER and SULLIVAN [75] identified a subset of patients $(n=13)$ with OSAHS, who were "grossly obese" $\left(\mathrm{BMI}>35 \mathrm{~kg} \cdot \mathrm{m}^{-2}\right)$, and in whom $\mathrm{CO}_{2}$ retention $(8.3 \pm 0.3 \mathrm{kPa})$ and nocturnal hypoventilation persisted in REM sleep, despite CPAP therapy. The study by PIPER and SulLIVAN [75] clearly showed that, among the markedly obese patients with OHS, there were some nonresponders to CPAP therapy who needed long-term NIV. It also showed that patients with hypercapnic OSAHS who fail to respond initially to nasal CPAP may need transient NIV as an interim measure. PeREZ DE LlANO et al. [76] described 54 patients with OHS $\left(44 \pm 9 \mathrm{~kg} \cdot \mathrm{m}^{-2}\right), 87 \%$ of whom had OSAHS. They were followed for a mean period of 50 months. BiPAP was used to treat 49 patients, and three received only nasal CPAP. In all, arterial oxygen tension $\left(\mathrm{Pa}_{2} \mathrm{O}_{2}\right), \mathrm{Pa}_{1} \mathrm{CO}_{2}$ and Epworth sleepiness scores were improved [76]. MASA et al. [77] showed that NIV was as efficient in correcting arterial blood gases after hypercapnic respiratory failure in patients with OHS, as in patients with kyphoscoliosis.

Two short-term studies tried to distinguish between obese patients who could be treated by CPAP alone and those who needed bi-level pressure support ventilation. RESTA et al. [78] included 105 OSAHS patients who underwent a first night with CPAP. Satisfactory results were obtained in $81(77 \%)$ patients, as monitored by polysomnography, while $24(23 \%)$ required bi-level pressure support ventilation. Patients in whom bi-level pressure support ventilation was mandatory had a higher BMI $\left(40 \pm 6\right.$ versus $\left.33 \pm 6 \mathrm{~kg} \cdot \mathrm{m}^{-2}\right)$, a lower forced expiratory volume in one second (FEV1), forced vital capacity (FVC), and FEV1/FVC ratio than patients who did well on CPAP. They also had a higher daytime $\mathrm{Pa}_{1} \mathrm{CO}_{2}(6.0 \pm 0.8$ versus $5.3 \pm 0.5 \mathrm{kPa}$ ), a lower $\mathrm{Pa}_{\mathrm{a}} \mathrm{O}_{2}$, and a lower mean nocturnal $\mathrm{Sa}, \mathrm{O}_{2}$. Although $96 \%$ of the patients with OSAHS could be managed with nasal CPAP, 65\% (11 out of 17) of those with associated OHS needed bi-level pressure support ventilation. RABEC et al. [79] studied 41 obese subjects hospitalised for an acute hypercapnic respiratory failure $\left(\mathrm{Pa}_{1} \mathrm{CO}_{2}>6.7 \mathrm{kPa}\right.$, mean 9.4), and treated with NIV. All but two patients improved their arterial blood gases under NIV. After the acute episode, nine patients with OSAHS were put on long-term nasal CPAP. A total of 29 patients were put on long-term bi-level pressure support ventilation. Patients who were treated with bi-level pressure support ventilation had either an associated OHS, or COPD. Their mean $\mathrm{Pa}_{1} \mathrm{CO}_{2}$ values were higher than patients discharged with nasal CPAP. SCHÄFER et al. [80] compared 13 
patients with OSAHS who failed to respond to initial CPAP therapy with a control group matched for AHI [80]. Nonresponders were significantly more obese (mean BMI $44 \pm 8$ versus $31 \pm 6 \mathrm{~kg} \cdot \mathrm{m}^{-2}$ ), had lower $\mathrm{Pa}_{\mathrm{a}_{2}} \mathrm{O}_{2}$ and higher $\mathrm{Pa}, \mathrm{CO}_{2}$ (mean values 5.9 versus $5.1 \mathrm{kPa}$ ) values, and spent more time with an $\mathrm{Sa}_{\mathrm{a}_{2}}<90 \%$ on nocturnal pulse oximeter tracings.

Recently, SCHÖNHOFER et al. [65] described 30 patients treated with home mechanical ventilation, eight $(26 \%)$ of whom were treated for OHS. This was the first report including such a large ratio of patients with $\mathrm{OHS}$ (mean (range) BMI of patients with OHS $\left.40(33.8-48.1) \mathrm{kg} \cdot \mathrm{m}^{-2}\right)$. A recent study [70] of 15 subjects with OHS showed that seven out of 15 had a low ventilatory response to $\mathrm{CO}_{2}$, and that these low responders increased their ventilatory response to $\mathrm{CO}_{2}$ by $47 \%$ after five nights of efficient NIV. NIV improved sleep structure in all subjects, significantly increasing stages 3-4 and REM sleep, whilst decreasing stage 1 sleep.

In the Lake Geneva area study [62], 71 patients, i.e. $33 \%$ of all patients included, were treated for OHS with $(n=50)$ or without OSAHS. All patients had presented at least one episode of acute hypercapnic respiratory failure. None of the patients included were treated by bi-level pressure support ventilation solely because of discomfort or intolerance to CPAP. Despite long-term treatment by NIV, mean daytime $\mathrm{Pa}_{1} \mathrm{CO}_{2}$ values without ventilation were slightly increased $(6.5 \pm 1.3 \mathrm{kPa})$; mean BMI was $41.9 \pm 9 \mathrm{~kg} \cdot \mathrm{m}^{-2}$. The majority of patients with OHS (82\%) were treated with bi-level pressure support ventilation. Mean values for inspiratory positive airway pressure were $1.8 \pm 0.3 \mathrm{kPa}$ (median 1.8, range 1.2 2.5 ), and for expiratory positive airway pressure: $0.7 \pm 0.3 \mathrm{kPa}$ (median 0.6, range 0.4-0.14). Probability of pursuing NIV was $76 \%$ at $3 \mathrm{yrs}$ and $72 \%$ at $5 \mathrm{yrs}$, i.e. the highest among all patients studied. Mortality was low $(6 \%)$, with a 5 -yr survival rate of $88 \%$. After starting home NIV, the number of days spent in hospital decreased significantly for 3 yrs when compared with the year before NIV.

In summary, although CPAP can improve arterial blood gases and nocturnal $\mathrm{Sa}_{2} \mathrm{O}_{2}$ in the majority of patients with OSAHS, there is clearly a subset of markedly obese patients (BMI $>35 \mathrm{~kg} \cdot \mathrm{m}^{-2}$ ), with daytime hypoventilation in whom longterm NIV (by means of bi-level pressure support ventilation) is necessary to correct these variables. The question of whether patients with OSAHS and OHS, treated by NIV, could be switched to nasal CPAP after a certain number of months without recurrent episodes of hypercapnic failure, has not been studied to date.

\section{CONCLUSIONS}

Central nonhypercapnic sleep apnoea and hypercapnic alveolar hypoventilation are serious disorders that are frequently encountered in sleep medicine. An extensive choice of treatment options is available for the management of idiopathic central sleep apnoea. The ultimate choice should rely on the current insights into the pathogenetic mechanisms in general, and the ones active in the patients to be treated.

CSR in patients with cardiac failure can be treated with CPAP or bi-level pressure support ventilation. Most published information is available on CPAP therapy. There is insufficient evidence to recommend bi-level pressure support ventilation rather than CPAP in patients with CSR. The question of whether CPAP or bi-level pressure support ventilation is indicated for any patients with CSR remains open, with current evidence derived from a large study on survival suggesting not. The treatment of symptomatic obstructive sleep apnoea in patients with significant cardiac failure is indicated per se. Patients may gain additional benefits in terms of improved cardiac function, which has been demonstrated with CPAP use. The question whether patients with heart failure who also have mild OSAHS should be treated with CPAP currently remains unanswered.

There is preliminary evidence that ASV controls CSR in patients with CHF. While ASV is not a first-line treatment choice, it proves superior to $\mathrm{O}_{2}, \mathrm{CPAP}$ and bi-level pressure support ventilation in controlling $\mathrm{AHI}$ and probably sleep fragmentation. There is a suggestion that ASV improves quality-of-life scores and cardiac function, but this has not yet been proven in large, prospective, randomised trials. There are no data regarding the impact on survival.

Both theophylline and acetazolamide have been shown to exert beneficial effects on CSR in terms of reduction of the AHI. Nocturnal $\mathrm{O}_{2}$ therapy also reduces CSR in a number of wellcontrolled but small studies. However, there is no convincing evidence of positive effects on cardiac function. New studies on a much broader scale are needed to investigate treatment effects of $\mathrm{O}_{2}$ and drugs. Administration of $\mathrm{CO}_{2}$ stabilises CSR by increasing $\mathrm{Pa}_{1} \mathrm{CO}_{2}$ far above the apnoeic threshold. Unfortunately, this treatment cannot be prescribed outside the experimental setting.

Noninvasive home ventilation is increasingly applied in obesity-hypoventilation syndrome patients with hypercapnic respiratory failure. This trend parallels, to some extent, the pandemic growth of the prevalence of obesity. While continuous positive airway pressure can control nocturnal arterial oxygen saturation values and restore normal ventilatory gas exchange in a majority of patients with obstructive sleep apnoea/hypopnoea syndrome, there is clearly a subset of markedly obese patients (body mass index $>35 \mathrm{~kg} \cdot \mathrm{m}^{-2}$ ) with daytime hypoventilation in whom long-term noninvasive ventilation should be considered. Anecdotal evidence exists that patients with obstructive sleep apnoea/hypopnoea syndrome and obesity-hypoventilation syndrome who require initial treatment with noninvasive ventilation can be subsequently switched to nasal continuous positive airway pressure without recurrent episodes of hypercapnic failure. However, further medical evidence must be collected to identify subgroups in whom this step-down procedure can be implemented as a standard procedure. Recent studies suggest a specific impact of noninvasive ventilation on ventilatory response to carbon dioxide, which has not been described with nasal continuous positive airway pressure.

\section{REFERENCES}

1 Sharp JT, Barrocas M, Chokroverty S. The cardiorespiratory effects of obesity. Clin Chest Med 1980; 1: 103-118.

2 Skatrud JB, Dempsey JA. Interaction of sleep state and chemical stimuli in sustaining rhythmic ventilation. J Appl Physiol 1983; 55: 813-822. 
3 De Backer WA. Central sleep apnoea, pathogenesis and treatment: an overview and perspective. Eur Respir J 1995; 8: 1372-1383.

4 De Backer WA. Sleep and breathing: actual insight and perspectives. Eur Respir J 1995; 8: 1071-1072.

5 De Backer WA. Methods and clinical significance of studying chemical drives. Respir Physiol 1998; 114: 75-81.

6 Badr MS, Toiber F, Skatrud JB, Dempsey J. Pharyngeal narrowing/occlusion during central sleep apnea. J Appl Physiol 1995; 78: 1806-1815.

7 Vanderveken OM, Oostveen E, Boudewyns AN, Verbraecken JA, Van de Heyning PH, De Backer WA. Quantification of pharyngeal patency in patients with sleep-disordered breathing. ORL J Otorhinolaryngol Relat Spec 2005; 67: 168-179.

8 De Backer W. Upper airway reflexes and obstructive sleep apnoea. Eur Respir J 1993; 6: 9-10.

9 Javaheri S. Central sleep apnea-hypopnea syndrome in heart failure: prevalence, impact, and treatment. Sleep 1996; 19: Suppl. 10, S229-S231.

10 Kohnlein T, Welte T, Tan LB, Elliott MW. Central sleep apnoea syndrome in patients with chronic heart disease: a critical review of the current literature. Thorax 2002; 57: 547-554.

11 Javaheri S, Parker TJ, Liming JD, et al. Sleep apnea in 81 ambulatory male patients with stable heart failure. Types and their prevalences, consequences, and presentations. Circulation 1998; 97: 2154-2159.

12 Sin DD, Fitzgerald F, Parker JD, Newton G, Floras JS, Bradley TD. Risk factors for central and obstructive sleep apnea in 450 men and women with congestive heart failure. Am J Respir Crit Care Med 1999; 160: 1101-1106.

13 Andreas S. Nocturnal insights in chronic heart failure. Eur Heart J 1999; 20: 1140-1141.

14 Verbraecken J, De Backer W, Willemen M, De Cock W, Wittesaele W, Van De Heyning P. Chronic $\mathrm{CO}_{2}$ drive in patients with obstructive sleep apnea and effect of CPAP. Respir Physiol 1995; 101: 279-287.

15 Verbraecken J, Willemen M, De Cock W, et al. Influence of long-term CPAP therapy on $\left.\mathrm{CO}_{2}\right)$ drive in patients with obstructive sleep apnea. Respir Physiol 2000; 123: 121-130.

16 Biberdorf DJ, Steens R, Millar TW, Kryger MH. Benzodiazepines in congestive heart failure: effects of temazepam on arousability and Cheyne-Stokes respiration. Sleep 1993; 16: 529-538.

17 Hardman JG, Limbird LE, Molinoff PB, Ruddon RW. In: Goodman and Gilman's The Pharmacological Basis of Therapeutics. McGraw-Hill, New York, 1996; pp. 672-682.

18 Funaya H, Kitakaze M, Node K, Minamino T, Komamura K, Hori M. Plasma adenosine levels increase in patients with chronic heart failure. Circulation 1997; 95: 1363-1365.

19 Engelstein ED, Lerman BB, Somers VK, Rea RF. Role of arterial chemoreceptors in mediating the effects of endogenous adenosine on sympathetic nerve activity. Circulation 1994; 90: 2919-2926.

20 Andreas S, Reiter H, Luthje L, et al. Differential effects of theophylline on sympathetic excitation, hemodynamics, and breathing in congestive heart failure. Circulation 2004; 110: 2157-2162.
21 Javaheri S, Parker TJ, Wexler L, Liming JD, Lindower P, Roselle GA. Effect of theophylline on sleep-disordered breathing in heart failure. $N$ Engl J Med 1996; 335: 562-567.

22 Pesek CA, Cooley R, Narkiewicz K, Dyken M, Weintraub NL, Somers VK. Theophylline therapy for near-fatal Cheyne-Stokes respiration. A case report. Ann Intern Med 1999; 130: 427-430.

23 De Backer WA, Verbraecken J, Willemen M, Wittesaele W, De Cock W, Van de Heyning P. Central apnea index decreases after prolonged treatment with acetazolamide. Am J Respir Crit Care Med 1995; 151: 87-91.

24 Sutton JR, Houston CS, Mansell AL, et al. Effect of acetazolamide on hypoxemia during sleep at high altitude. N Engl J Med 1979; 301: 1329-1331.

25 Nakayama H, Smith CA, Rodman JR, Skatrud JB, Dempsey JA. Effect of ventilatory drive on carbon dioxide sensitivity below eupnea during sleep. Am J Respir Crit Care Med 2002; 165: 1251-1260.

26 Javaheri S. Acetazolamide improves central sleep apnea in heart failure: a double-blind, prospective study. Am J Respir Crit Care Med 2006; 173: 234-237.

27 Krachman SL, D'Alonzo GE, Berger TJ, Eisen HJ. Comparison of oxygen therapy with nasal continuous positive airway pressure on Cheyne-Stokes respiration during sleep in congestive heart failure. Chest 1999; 116: 1550-1557.

28 Walsh JT, Andrews R, Starling R, Cowley AJ, Johnston ID, Kinnear WJ. Effects of captopril and oxygen on sleep apnoea in patients with mild to moderate congestive cardiac failure. Br Heart J 1995; 73: 237-241.

29 Hanly PJ, Millar TW, Steljes DG, Baert R, Frais MA, Kryger MH. The effect of oxygen on respiration and sleep in patients with congestive heart failure. Ann Intern Med 1989; 111: 777-782.

30 Andreas S, von zur Mühlen F, Stevens J, Kreuzer H. Nocturnal oxygen and hypercapnic ventilatory response in patients with congestive heart failure. Respir Med 1998; 92: 426-431.

31 Javaheri S, Ahmed M, Parker TJ, Brown CR. Effects of nasal $\mathrm{O}_{2}$ on sleep-related disordered breathing in ambulatory patients with stable heart failure. Sleep 1999; 22: 1101-1106.

32 Staniforth AD, Kinnear WJ, Starling R, Hetmanski DJ, Cowley AJ. Effect of oxygen on sleep quality, cognitive function and sympathetic activity in patients with chronic heart failure and Cheyne-Stokes respiration. Eur Heart J 1998; 19: 922-928.

33 Arzt M, Schulz M, Wensel R, et al. Nocturnal continuous positive airway pressure improves ventilatory efficiency during exercise in patients with chronic heart failure. Chest 2005; 127: 794-802.

34 Sasayama S, Izumi T, Seino Y, Ueshima K, Asanoi H. Effects of nocturnal oxygen therapy on outcome measures in patients with chronic heart failure and Cheyne-Stokes respiration. Circ J 2006; 70: 1-7.

35 Franklin KA, Eriksson P, Sahlin C, Lundgren R. Reversal of central sleep apnea with oxygen. Chest 1997; 111: 163-169.

36 Mak S, Azevedo ER, Liu PP, Newton GE. Effect of hyperoxia on left ventricular function and filling pressures in patients with and without congestive heart failure. Chest 2001; 120: 467-473. 
37 Haque WA, Boehmer J, Clemson BS, Leuenberger UA, Silber DH, Sinoway LI. Hemodynamic effects of supplemental oxygen administration in congestive heart failure. $J$ Am Coll Cardiol 1996; 27: 353-357.

38 Andreas S, Weidel K, Hagenah G, Heindl S. Treatment of Cheyne-Stokes respiration with nasal oxygen and carbon dioxide. Eur Respir J 1998; 12: 414-419.

39 Naughton MT, Benard DC, Rutherford R, Bradley TD. Effect of continuous positive airway pressure on central sleep apnea and nocturnal $\mathrm{PCO}_{2}$ in heart failure. Am J Respir Crit Care Med 1994; 150: 1598-1604.

40 Naughton MT, Benard DC, Liu PP, Rutherford R, Rankin F, Bradley TD. Effects of nasal CPAP on sympathetic activity in patients with heart failure and central sleep apnea. Am J Respir Crit Care Med 1995; 152: 473-479.

41 Sin DD, Logan AG, Fitzgerald FS, Liu PP, Bradley TD. Effects of continuous positive airway pressure on cardiovascular outcomes in heart failure patients with and without Cheyne-Stokes respiration. Circulation 2000; 102: 61-66.

42 Willson GN, Wilcox I, Piper AJ, et al. Noninvasive pressure preset ventilation for the treatment of Cheyne-Stokes respiration during sleep. Eur Respir J 2001; 17: 1250-1257.

43 Kasai T, Narui K, Dohi T, et al. Efficacy of nasal bi-level positive airway pressure in congestive heart failure patients with Cheyne-Stokes respiration and central sleep apnea. Circ J 2005; 69: 913-921.

44 Kohnlein T, Welte T, Tan LB, Elliott MW. Assisted ventilation for heart failure patients with Cheyne-Stokes respiration. Eur Respir J 2002; 20: 934-941.

45 Bradley TD, Logan AG, Kimoff RJ, et al. Continuous positive airway pressure for central sleep apnea and heart failure. N Engl J Med 2005; 353: 2025-2033.

46 Liston R, Deegan PC, McCreery C, Costello R, Maurer B, McNicholas WT. Haemodynamic effects of nasal continuous positive airway pressure in severe congestive heart failure. Eur Respir J 1995; 8: 430-435.

47 Gabor JY, Newman DA, Barnard-Roberts V, et al. Improvement in Cheyne-Stokes respiration following cardiac resynchronisation therapy. Eur Respir J 2005; 26: 95-100.

48 Sinha AM, Skobel EC, Breithardt OA, et al. Cardiac resynchronization therapy improves central sleep apnea and Cheyne-Stokes respiration in patients with chronic heart failure. J Am Coll Cardiol 2004; 44: 68-71.

49 Mansfield DR, Gollogly NC, Kaye DM, Richardson M, Bergin P, Naughton MT. Controlled trial of continuous positive airway pressure in obstructive sleep apnea and heart failure. Am J Respir Crit Care Med 2004; 169: 361-366.

50 Kaneko Y, Floras JS, Usui K, et al. Cardiovascular effects of continuous positive airway pressure in patients with heart failure and obstructive sleep apnea. N Engl J Med 2003; 348: 1233-1241.

51 Mayer J, Weichler U, Herres-Mayer B, Schneider H, Marx U, Peter JH. Influence of metoprolol and cilazapril on blood pressure and on sleep apnea activity. J Cardiovasc Pharmacol 1990; 16: 952-961.

52 Weichler U, Herres-Mayer B, Mayer J, Weber K, Hoffmann R, Peter JH. Influence of antihypertensive drug therapy on sleep pattern and sleep apnea activity. Cardiology 1991; 78: 124-130.
53 Dark DS, Pingleton SK, Kerby GR, et al. Breathing pattern abnormalities and arterial oxygen desaturation during sleep in the congestive heart failure syndrome. Improvement following medical therapy. Chest 1987; 91: 833-836.

54 Tomcsanyi J, Karlocai K, Papp L. Disappearance of periodic breathing after heart operations. I Thorac Cardiovasc Surg 1994; 107: 317-318.

55 Topfer V, El Sebai M, Wessendorf TE, Moraidis I, Teschler H. Adaptive servoventilation: effect on CheyneStokes respiration and on quality of life. Pneumologie 2004; 58: 28-32.

56 Schadlich S, Konigs I, Kalbitz F, Blankenburg T, Busse HJ, Schutte W. Cardiac efficiency in patients with CheyneStokes respiration as a result of heart insufficiency during long-term nasal respiratory treatment with adaptive servo ventilation (AutoSet CS). Z Kardiol 2004; 93: 454-462.

57 Teschler H, Dohring J, Wang YM, Berthon-Jones M. Adaptive pressure support servo-ventilation: a novel treatment for Cheyne-Stokes respiration in heart failure. Am J Respir Crit Care Med 2001; 164: 614-619.

58 Vogt-Ladner G, Worth H, Schacher C, Vogt M, Teschler H. Nasal ventilation with Autoset-CS versus nocturnal oxygen therapy (NOT) in patients with severe chronic heart failure (CHF) and Cheyne-Stokes respiration (CSR): long term effects on quality of sleep. Am J Respir Crit Care Med 2003; 167: A836.

59 Pepperell JC, Maskell NA, Jones DR, et al. A randomized controlled trial of adaptive ventilation for Cheyne-Stokes breathing in heart failure. Am J Respir Crit Care Med 2003; 168: 1109-1114.

60 Philippe C, Stoica-Herman M, Drouot X, et al. Compliance with and effectiveness of adaptive servoventilation versus continuous positive airway pressure in the treatment of Cheyne-Stokes respiration in heart failure over a six month period. Heart 2006; 92: 337-342.

61 Nowbar S, Burkart KM, Gonzales R, et al. Obesityassociated hypoventilation in hospitalized patients: prevalence, effects, and outcome. Am J Med 2004; 116: $1-7$.

62 Janssens JP, Derivaz S, Breitenstein E, et al. Changing patterns in long-term noninvasive ventilation: a 7-year prospective study in the Geneva Lake area. Chest 2003; 123: 67-79.

63 Leger P, Bedicam JM, Cornette A, et al. Nasal intermittent positive pressure ventilation. Long-term follow-up in patients with severe chronic respiratory insufficiency. Chest 1994; 105: 100-105.

64 Simonds AK, Elliott MW. Outcome of domiciliary nasal intermittent positive pressure ventilation in restrictive and obstructive disorders. Thorax 1995; 50: 604-609.

65 Schönhofer B, Sonneborn M, Haidl P, Bohrer H, Kohler D. Comparison of two different modes for noninvasive mechanical ventilation in chronic respiratory failure: volume versus pressure controlled device. Eur Respir J 1997; 10: 184-191.

66 Eichholzer M, Luthy J, Gutzwiller F. Epidemiology of overweight in Switzerland: results of the Swiss National Health Survey 1992-93. Schweiz Med Wochenschr 1999; 129: 353-361. 
67 Seidell JC. Obesity in Europe: scaling an epidemic. Int J Obes Relat Metab Disord 1995; 19: Suppl. 3, S1-S4.

68 Flegal KM, Carroll MD, Kuczmarski RJ, Johnson CL. Overweight and obesity in the United States: prevalence and trends, 1960-1994. Int J Obes Relat Metab Disord 1998; 22: $39-47$.

69 Redolfi S, Corda L, La Piana G, Spandrio S, Prometti P, Tantucci C. Long-term non-invasive ventilation increases chemosensitivity and leptin in obesity-hypoventilation syndrome. Respir Med 2007; 101: 1191-1195.

70 Chouri-Pontarollo N, Borel JC, Tamisier R, Wuyam B, Levy P, Pepin JL. Impaired objective daytime vigilance in obesity-hypoventilation syndrome: impact of noninvasive ventilation. Chest 2007; 131: 148-155.

71 Pankow W, Hijjeh N, Schuttler F, et al. Influence of noninvasive positive pressure ventilation on inspiratory muscle activity in obese subjects. Eur Respir J 1997; 10: 2847-2852.

72 Sullivan CE, Berthon-Jones M, Issa FG. Remission of severe obesity-hypoventilation syndrome after short-term treatment during sleep with nasal continuous positive airway pressure. Am Rev Respir Dis 1983; 128: 177-181.

73 Sanders MH, Kern N. Obstructive sleep apnea treated by independently adjusted inspiratory and expiratory positive airway pressures via nasal mask. Physiologic and clinical implications. Chest 1990; 98: 317-324.
74 Bott J, Baudouin SV, Moxham J. Nasal intermittent positive pressure ventilation in the treatment of respiratory failure in obstructive sleep apnoea. Thorax 1991; 46: 457-458.

75 Piper AJ, Sullivan CE. Effects of short-term NIPPV in the treatment of patients with severe obstructive sleep apnea and hypercapnia. Chest 1994; 105: 434-440.

76 Perez de Llano LA, Golpe R, Ortiz PM, et al. Short-term and long-term effects of nasal intermittent positive pressure ventilation in patients with obesity-hypoventilation syndrome. Chest 2005; 128: 587-594.

77 Masa JF, Celli BR, Riesco JA, Hernandez M, Sanchez DC, Disdier $\mathrm{C}$. The obesity hypoventilation syndrome can be treated with noninvasive mechanical ventilation. Chest 2001; 119: 1102-1107.

78 Resta O, Guido P, Picca V, et al. Prescription of nCPAP and nBIPAP in obstructive sleep apnoea syndrome: Italian experience in 105 subjects. A prospective two centre study. Respir Med 1998; 92: 820-827.

79 Rabec C, Merati M, Baudouin N, Foucher P, Ulukavac T, Reybet-Degat O. Management of obesity and respiratory insufficiency. The value of dual-level pressure nasal ventilation. Rev Mal Respir 1998; 15: 269-278.

80 Schäfer H, Ewig S, Hasper E, Luderitz B. Failure of CPAP therapy in obstructive sleep apnoea syndrome: predictive factors and treatment with bilevel-positive airway pressure. Respir Med 1998; 92: 208-215. 